\title{
Formation of research competence in university project-oriented training
}

\author{
Yuri Loginov $^{1 \mathrm{a}}$ and Igor Kovalev ${ }^{1}$ \\ ${ }^{1}$ Siberian State Aerospace University, Krasnoyarsk, Russia
}

\begin{abstract}
The aim of the study was to investigate the efficiency of research competence formation of aerospace university students in conditions of project-oriented training. The technology of project-oriented training of students in the form of a unique project for the development and creation of a series of student scientific-educational small satellites was implemented. To assess the effectiveness of the system of formation of research competencies a set of criterion-oriented test tasks was developed. In the experiment was attended by 130 students of the Institute of mechanical engineering and mechatronics, consisting of three control and three experimental training groups. The experiment was carried out step by step monitoring of the process of formation of research competence at the end of the third and fourth years of study. Comparative analysis of the results showed a positive trend in all indicators in the structure of research skills.
\end{abstract}

Keywords: project-oriented training, aerospace university students, efficiency of research

\section{Introduction}

The emergence of high-tech and science intensive industries, the dynamic growth of scientific and technical information, the creation of complex automated production systems requires the engineer a good fundamental training, the ability to quickly absorb the latest technology, the readiness to improve of facilities and means of engineering work. In this regard, the future of engineer training should be aimed at the formation of competences, focused on the development of creative thinking, inventiveness, the ability to solve research problems, skills of independent search activity.

One of the most important competencies is a research competence [1], which provides an opportunity for students with available to them the knowledge and skills to model, analyze, and transform (modify on a background of varying professional tasks) the objects of professional activities, showing the activity, the ability to make their own decisions and take responsibility for them, critically evaluate the results of their actions.

\footnotetext{
a Corresponding author: loginov@sibsau.ru
} 
As a basic principle, which determines the approach to the process of forming of research competence, we used the principle of project-oriented modeling that defines the strategy for training and research activities as a system of increasingly complex simulated objects of professional activity, allowing a high degree of reliability to evaluate the objects themselves and identify their connection with other objects.

Competence is a complex system, which is based upon the three common and wellunderstood categories such as knowledge, abilities and skills. In our view, a separate subsystem in the structure of competence, which is a kind of an add-on knowledge and skills, is a subsystem of analysis and management of these categories in order to maintain the capacity of the knowledge according to the current state of the object of professional activity. In our understanding, the competence is formed exclusively as a result of interaction of the specialist with the real object of professional activity.

To determine the substantive content of the research competence structure is fundamentally important to proceed from the fact that it is specified in a set of interrelated personality characteristics [2], including:

- sustained motivation and high moral and ethical values;

- personal qualities (perseverance, persistence, responsibility);

- scientific, methodological and legal knowledge;

- research abilities and skills (cognitive, subject-specific, technological, communicative, organizational, design, creative);

- experience the famous and creative ways, creative methods of research.

The process of development the research competence of students should be focused on the implementation of their research and personal potential, formation of readiness for creative activity [3].

Here are the components of this process:

- Ability to organize own work, choose standard methods and ways to perform professional tasks, to assess their effectiveness and quality;

- Search and use of information necessary for the effective performance of professional tasks, professional and personal development;

- Use information and communication technologies in professional activity;

- Independently determine the problem of professional and personal development, self-education, consciously plan improvement of professional skill.

Formation of research competence involves the use of interactive teaching methods, not only in the preparation of course work, but also in the study of various disciplines during the passage educational and industrial practices, the results of which may also be submitted via electronic presentations. In demand are elective courses "Fundamentals of educational and research activities," "Search, analysis and presentation of textual information." It seems important and the involvement of students in the scientific community.

Important ways of research abilities of students are active learning methods. One of the leading places is occupied by the project method. The project-based method is the development of cognitive skills, abilities independently to use their knowledge and skills to navigate in the information space. Project-based learning requires the integration of knowledge, skills to apply knowledge from various fields of science and technology, technology and creative areas [4].

Project method is a flexible model of organization of the educational process that focuses on self-development, creative self-realization of the individual student and aiming at the formation of the research competence. Performance analysis on the formation of the research competence through project activities suggests that it provides an increase in the quality of theoretical knowledge and practical skills of students, formation of students' ability to apply research methods in the course of practice, orientation of students on creativity and autonomy. 
Thus, the problem of the study is to find effective ways of forming of research competence of the future engineer on the basis of project-oriented modeling while studying at the Technical University.

The aim of the study was to investigate the efficiency of research competence formation of aerospace university students in conditions of project-oriented training.

\section{Methods}

To evaluate the efficiency of the system of research abilities formation a set of criterionoriented test tasks has been developed. We used methods of pedagogical diagnostics and testing, pedagogical observation, conversation, questionnaire, statistical processing of results of experimental work and analysis.

Following research objectives have been identified:

- Study the effectiveness of research competence in a project-oriented training at university;

- Define the requirements to the educational environment which allow to effectively form the research competence of University students;

- Develop a set of research tasks, which allows students to develop research capacity and to propose a methodical approach its implementation;

- Develop criteria for evaluating the formation of research competence.

\section{Results and discussion}

The first stage of changes was implemented in the educational process to ensure the implementation of the principle of project-based learning.

For this purpose, the training process was implemented technology of project-oriented training of students in the form of a unique project for the development and creation of a series of student scientific-educational small satellites (Smallsat) [5]. The integrated system of training engineers for the aerospace industry using innovative technology project-based learning student is actively developing in the Siberian State Aerospace University for several years in cooperation with an industrial partner of JSC "Information Satellite Systems" (JSC «ISS»). Students from the third year take part in all stages of satellite production from the development of project documentation to the control satellite in orbit. Scheme of the project-oriented training of engineers is shown in Fig. 1.

The industrial partner of the University JSC "ISS" is a leading enterprise of the Russian space industry. The company works in all fields of satellite production - from spacecraft design to satellite flight path control at low circular and geostationary orbits.

Resource Centre of the University "Spacecraft and Systems" has been engaged in the design and assembly of a series of scientific and educational small satellites for a number of years. The project is carried out by a team of students, postgraduate students, young scientists, and specialists of JSC "ISS"; the team is also responsible for conducting scientific and technological experiments in space. The Centre's equipment enables the assembly and testing of satellite mechanical systems, electronic equipment prototyping, conducting vacuum and climate tests, researching spacecraft electronic equipment. Students take part in all stages of satellite production from the development of project documentation to the control satellite in orbit.

Implementing the project allows to identify the students who have shown their best effort and enjoyed laboratory work not only during their main curricula, but in related 
extracurricular activities. This experience shows that such students subsequently become the most qualified and responsible professionals.

Typically, the third, fourth, and fifth-year students simultaneously participate in the project. They specialize in the areas of aircraft control systems, rocket complexes and astronautics, geodesy and remote sensing. Students of other courses also have an opportunity to participate in the project, for example, students of marketing and high technologies management. Each student must undergo a research practice, find two research supervisors - one must be an academic staff member of the Siberian State Aerospace University; the other should be a leading specialist at JSC "ISS".

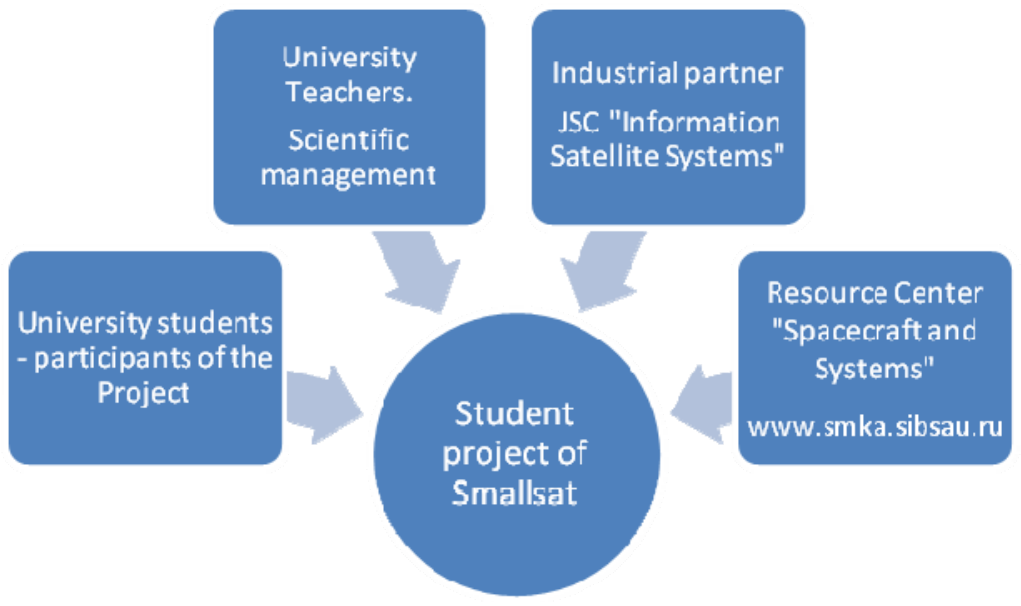

Fig. 1. Scheme of the project-oriented training of engineers

Resource Centre of the University "Spacecraft and Systems" has been engaged in the design and assembly of a series of scientific and educational small satellites for a number of years. The project is carried out by a team of students, postgraduate students, young scientists, and specialists of JSC "ISS"; the team is also responsible for conducting scientific and technological experiments in space. The Centre's equipment enables the assembly and testing of satellite mechanical systems, electronic equipment prototyping, conducting vacuum and climate tests, researching spacecraft electronic equipment. Students take part in all stages of satellite production from the development of project documentation to the control satellite in orbit.

Implementing the project allows to identify the students who have shown their best effort and enjoyed laboratory work not only during their main curricula, but in related extracurricular activities. This experience shows that such students subsequently become the most qualified and responsible professionals.

Typically, the third, fourth, and fifth-year students simultaneously participate in the project. They specialize in the areas of aircraft control systems, rocket complexes and astronautics, geodesy and remote sensing. Students of other courses also have an opportunity to participate in the project, for example, students of marketing and high technologies management. Each student must undergo a research practice, find two research supervisors - one must be an academic staff member of the Siberian State Aerospace University; the other should be a leading specialist at JSC "ISS".

The construction project of the students' satellite is divided into twelve directions. This models the number of main satellite subsystems - the thermal control subsystem, the 
electric power subsystem, the attitude determination and control subsystem, etc. The thirteenth direction comprises the design of payload equipment for the satellite. Further in the project, this direction is responsible for performing scientific and educational experiments in space. The scientific work of each member of the student team must be done in one of these areas. When the student accomplishes his first year on the project, he or she becomes a tutor for younger student of the same direction, sharing the acquired experience.

The final results of the student's scientific work in the selected direction, including the graduation project and diploma thesis, is the design and manufacturing of a functional satellite component or constructional element. This part will be installed inside an actual satellite, which will be then launched into space. The telemetry data from this device will be received and processed at the University's Satellite Control Center. After the defense of the diploma project the student is qualified for employment at JSC "ISS". He will be working with their scientific adviser at the same department. This ensures the student has already got a significant background and experience in practical design. Simultaneously, the graduates also can continue their studies in postgraduate course at University.

A specialized internet-portal has been developed at www.smka.sibsau.ru along with a projects management system for project monitoring. This enables the remote coordination of joint projects between different higher education facilities, bringing together students from different cities.

Technology project-based learning provides high quality training, ensures graduates a competitive advantage in the labor market and their effective work in the industry and other high-tech enterprises. Typically, to the end of training most of the graduates are employed on the profile of obtained specialty. The high level of preparation is also confirmed by team and individual prizes, regularly won by University students in contests and competitions on different disciplines, such as theoretical mechanics, strength of materials, programming, computer graphics, information technology security and management.

Direct involvement of students in practical works on designing, manufacturing, testing, preparation for launch and flight control of scientific and educational satellites significantly increases the level of training and developing research competence. The practical experience gained by students in the course of work on the creation of university satellites, significantly reduces the time of their adaptation to the implementation of specific production problems at the enterprises of space industry and the formation of young professional as an authoritative member of the labor collectives.

Great importance in the formation of research competences for our study had a control and evaluation of students' achievements. To assess the effectiveness of the system of formation of research competencies a set of criterion-oriented test tasks was developed. The study was carried out on the basis of the Siberian State Aerospace University.

In the experiment, was attended by 130 students of the Institute of mechanical engineering and mechatronics, consisting of three control and three experimental training groups of the third and then the fourth years.

During the training were held extra classes, which clarified the nature of research competence and the role of scientific and research activities, as well as to focus attention on the need for the formation of research competence, taking into account the specifics and problems of further professional activities.

In the fourth year of study in the design of research tasks main target setting has been made to maximize the autonomy of research activities, enabling learners to assess their research capabilities, thus learn to maintain cognitive component of future professional activity at the required level.

The experiment was carried out step by step monitoring of the process of formation of research competence at the end of the third and fourth years of study. Monitoring was 
carried out in three main features: the ability of planning, analysis and control, and readiness to study.

Figure 2 shows the results of analysis of formation of research competence in the course of monitoring on three main signs.

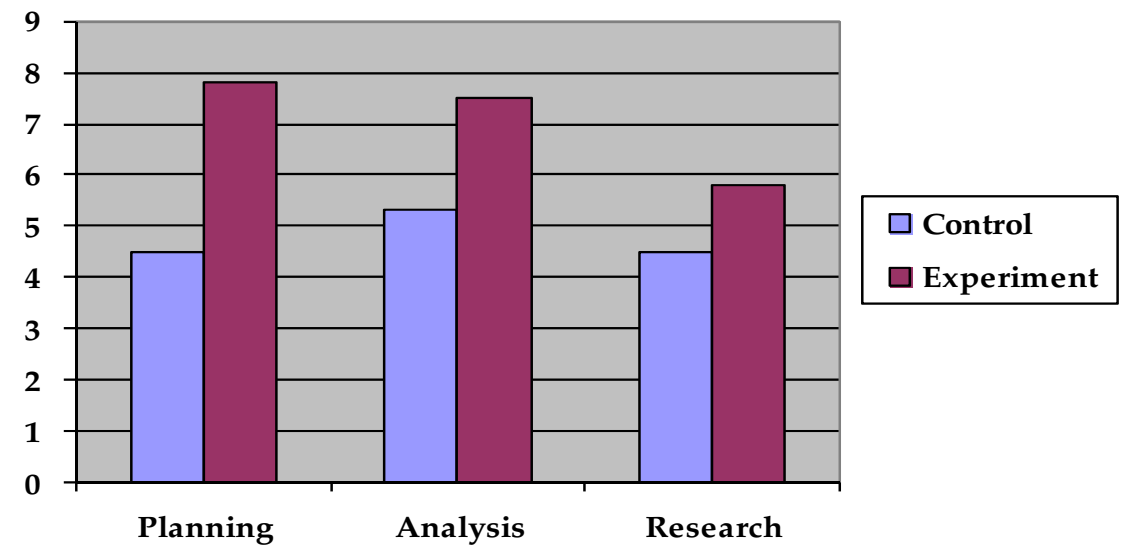

Fig. 2. Signs of research competence in students of the control and experimental groups at the end of the fourth year (averages on a ten-point scale)

Figure 2 shows that the experimental groups all signs observed excess values compared to the control groups.

Monitoring of the process of formation of research competence at the end of the fourth year showed that students of experimental groups have formed an idea about the study as a holistic event, containing planning, organizational-control and analytical components.

Comparative analysis of the results showed a positive trend in all indicators in the structure of research skills. So, the organization of proposed a package of measures within the framework of educational programs for the design and mathematical modeling have provided not only introduction to the scientific work and the implementation of the project, but also a significant increase in the level of work. For the formation of skills necessary for research the performance of works containing elements of research were included. Students received knowledge and skills the research orientation, which influenced the attitude to the profession, led to realize the necessity of mathematical methods development for future professional activities.

It was found that the percentage of students who meet the criteria of formation of research competence, according to experts in the control groups was $28 \%$, while in the experimental group, the figure was $46 \%$. It should be noted that in the experimental groups were the students with the research competencies are not only general and applied, but also of a professional nature. The percentage of students who have research competencies of applied nature in the experimental groups is significantly higher (15\%) compared with the control groups $(5.8 \%)$.

Implementation of student research and participation in research projects influenced the development of the intuition and the ability to assess compliance with the outcome predetermined benchmark requirements. Appeared ability to organize information and make generalizing conclusions, think logically.

Here are the main components of the method of project-based learning that allows arranging the research competence of technical universities students: 
- Creating a space of interaction of the teacher and the student, allowing the student to take the most favorable model of professional activity and exercise early professional selfdetermination;

- Provision of student development opportunities in terms of competency, namely, in the formation and development of the components of the subsystem analysis and management as part of the student's competence;

- Creation of a clear understanding of students about the subjects and occupations;

- Possibility of versatile modeling of objects of professional activity.

Developed and experimentally tested structural and logical model of the student's research competence formation assumes prerequisites for further improvements, which are primarily seen in the development of technologies of the student's research competence formation, allowing carrying out this process on a more high organizational and methodological level.

\section{Conclusions}

Created and tested the educational environment in the form of project-based learning that allows to effectively generating research competence in students, the most favorable way to perceive the professional activity and exercise early professional self-determination. Technology of project-based learning ensures the development of research competencies, the high quality of the training of engineers, ensures graduates a competitive advantage in the labor market and their effective work at the industrial enterprises.

Experimental verification of the results of the study using a phased monitoring showed the effectiveness of the developed structural-logical model of the research competence formation of Aerospace University students.

As a part of general professional and special disciplines have been developed a set of research tasks of varying complexity, focused on the individual approach to the student, to unleash the research potential and show the ability of students to independent study of real and simulated objects of professional activity.

The practical significance of the study lies in the fact that the implemented projectoriented learning method allows to generate the research competence of students as the basis of professional competence of the future specialist.

\section{References}

1. A. A. Chervova, I. A. Yanyuk, Formation of research abilities of students of high schools. Science and School, Moscow: MSPU, 6, 11-14 (2007)

2. Y. A. Komarova, Research competence of specialists: functional and informative description. Proceedings of the Russian State Pedagogical University. St. Petersburg, 11 (68), 69-77 (2008)

3. E. N. Lekomtseva, Scientific research competence of bachelor. Yaroslavl Pedagogical Gazette. 3, 92-96 (2009)

4. E.S. Polat. Method of projects. Electronic resource // http //: wiki.iteach.ru (2003)

5. I. V. Kovalev, Y. Y. Loginov, P.V. Zelenkov, An integrated system of training engineers for aerospace industry in Siberia using innovative technology of the student project-and-team work. Procedia - Social and Behavioral Sciences, 174, 537-543 (2015) 